\title{
Time Management, External Motivation, and Students' Academic Performance: Evidence from a Malaysian Public University
}

\author{
Abdul Rahman Hamzah ${ }^{1}$, Esuh Ossai-Igwe Lucky ${ }^{1} \&$ Mohd Hasanur Raihan Joarder ${ }^{1}$ \\ ${ }^{1}$ College of Business, Universiti Utara Malaysia, Malaysia \\ Correspondence: Abdul Rahman Hamzah, College of Business, Universiti Utara Malaysia, Malaysia. E-mail: \\ hamzahd@uum.edu.my
}

Received: March 3, 2014 Accepted: April 24, 2014 Online Published: June 25, 2014

doi:10.5539/ass.v10n13p55 URL: http://dx.doi.org/10.5539/ass.v10n13p55

\begin{abstract}
Societies all over the world have used education as the instrument for the national development while students' academic performance has the real impact on their professional career development. There are many factors which can directly affect students' academic performance. However, after extensive reviews of the past literatures, the researchers argued that time management and external motivation have relatively higher influences on students' academic performance. The quantitative questionnaire survey method was employed for this study. The findings of the study indicated that there is a significant and positive relationship between time management and students' academic performance. In the light of the findings, we discuss the importance of time management in order to improve students' academic performance. Implications, suggestions and recommendations for students, parents, policy makers and educational stakeholders were discussed.
\end{abstract}

Keywords: time management, external motivation, students' academic performance, Universiti Utara Malaysia

\section{Introduction}

There is no doubt that today's students are the future leaders for nation building. However, the journey of transforming a nation's dreams into reality is not easy. Students in every discipline in universities should overcome various obstacles in order to achieve better academic performance measured by the GPA system. The Grade Point Average (GPA) system, as an indicator of the students' academic performance, is used in many countries around the world (James \& Chilvers, 2001; Svanum \& Zody, 2001). Malaysia is no exception. It is not necessarily true that a high level of academic performance will always be associated with a high intelligence quotient or hard work. Thus, the factors that influence students' academic performance needs to be identified and improved by university management, faculty and students in order to deliver superior academic performance (Womble, 2003). Some factors can be cited as the barriers to students' high performance during the stay at the university. These factors may be categorised as a cognitive and learning factors, social activities, job responsibilities (Devadoss \& Foltz, 1996). According to Sansgiry, Bhosle, and Sail, (2006) and Womble, (2003), among the various factors cited by previous researchers, cognitive and learning issues for example, time management skills play a significant role in achieving students' academic performance, while psychologists believe that motivation seems to be gaining more popularity, and seems to be a necessary ingredient for learning which is essential for students' higher performance (Tella, 2007; Biehler \& Snowman, 1986). There are some evidence that highlighted the relationship between these factors and students' academic performance. However, there is hardly any study done, particularly in the context of Malaysia, combining effects of cognitive and motivation factors on students' academic performance. Thus, the study has attempted to examine the effects of time management and external motivation on students' academic performance in Malaysia.

Needless to say that the university student is working hard in order to achieve best results in terms of grade point average at the undergraduate and postgraduate levels due to the extreme difficulty in job search competition in the labour market after their graduation. For the case of public universities in Malaysia, Universiti Utara Malaysia (UUM) was selected where in most cases students are required to take six to seven subjects for each semester of 14 weeks excluding revision/examination weeks. This is quite tight schedule and burdensome especially for those who do not have outstanding photographic memory. As a result, time management is one of the critical factors which will directly influence student academic performance. A proper time management skill may help university students especially UUM students to overcome and manage the tight schedule effectively. 
According to Tureman and Hartley (1996), time management is positively related to academic performance. The improper allocation of time, no setting goals and priority, spending more time with friends or last minutes preparation for examination, are some of the examples for poor time management behaviour which have been commonly discussed as a prime source of weak academic performance (Gall, 1988; Longman \& Atkinson, 1988; Walter \& Siebert, 1981).

According to Herzberg's (1959) theory, motivation drives people to perform better in his or her task. Academic performance is also influenced by motivational forces as researchers found motivation is positively related to their academic performance (Vansteenkiste, Zhou, Lens, \& Soenens, 2005). Recently, in the study of Afzal, Ali, Khan and Hamid (2010) stated that students' motivation plays an important role in higher education considering the importance of superior academic performance in their professional life. Realistically, it is true particularly in the part of the world where academic performance and better job opportunity has a strong relationship. One can assume that due to higher external motivation, students have poor academic performance. Truly, there are factors such as social isolation, huge academic pressure; financial difficulties and homesickness are some of the problems faced by university students nowadays (Fisher \& Hood, 1987). There are some evidence which are related to students' social motivation, and their relationship with lecturers and friends, seriously affect their academic performance (Juvonen \& Wentzel, 1996). Social support, as commonly believed to be the source of external motivation, serves as a buffer against these stressors. Perceived social support is expected to contribute to the better academic performance by reducing the pressure of academic life (Lakey \& Cohen, 2000). Besides that, socio- economic status or the financial position of the family and the students' academic success have proven a positive relation, which could be one of the external motivation factors as explained by many researchers (Jeynes, 2002; Barry, 2006 and Caro, 2009). Recently, Cohan and Khan (2010) found that the parents' contribution to their children's education has a constant and constructive effect on educational achievement. The other study by Gülerg and Emeç (2006) found that students who are satisfied with their lives, the ones with lower income level and whose parents stay together have better academic performance. Furthermore, Güncer and Köse (1993) affirmed the importance of family conditions on the academic accomplishment of a person. Since there are only a few empirical studies attempted to test these relationships, in an effort to correct this deficiency, we have designed our study to investigate the relationships of students' time management and external motivation with their academic performance in the context of Malaysian public universities with a sample from Universiti Utara Malaysia (UUM). It is postulated that an effective time management and the existence of external motivation can directly boost students' academic performance.

\section{Literature Review}

\subsection{Time Management}

Poor time management behaviors such as improper allocation of time or last -minute preparation for examinations, have been frequently been discussed as one of the prime source of poor academic performance (Gall, 1988; Longman \& Atkinson, 1988). It is quite a common practice that students become overcome with feelings that there is not sufficient time to perform their all tasks adequately. It is mostly because of inefficiency in time management. According to Campbell and Svenson (1992), time management refers to the way students manage their time in order to have better academic performance which is invaluable for academic success. Thus, it is important for students to know the first step of time management i.e. giving priority to the important matters, and should remain focused on issues essential for success (Walker \& Siebert, 1980). In line with these notions, Gloe (1999) argued that the techniques of time management are the best ways to manage course materials successfully. These includes group discussion, exchanging ideas and sharing views on key points, which ultimately help students to perform better in the examination leads to superior academic performance. Other researchers have described time management as the way by which an individual more efficiently accomplishes tasks and goals (Schuler, 1979); having balance, flexibility, and control over time (Lakein, 1973); setting priorities and scheduling tasks (Jordan, Cobb, \& McCully, 1989). Recently, Kaushar (2013) found that time management plays a vital role in students' academic performance. The researcher also argued that lack of time management skills act as the barrier to better academic performance.

According to Sansgiry, Kawatkar, Dutta, and Bhosle (2004), the basic time management skills begin with prioritizing, placing more emphasis on important tasks, being able to say 'no' to less important issue, and being able to stop and start immediately specific activities at pre-set schedules. They have also argued that implementing such strategy related to time management, one must engage in a "to do" list and need discipline to stay focused with the list in order to have better management of one's available time. Thus, students may avoid the last-minute aggressive study options before examination. According to Sansgiry et al. (2004), one such technique of time management is forming study groups (originally cited in the study of Gloe, 1999). An ideal 
group consists of about 3 or 4 students who study together and have discussions on a particular topic of interest. This is one of the constructive ways of sharing knowledge to each other, and remains refreshed with different views exposed by group members on same topic of interest. Other important issues related to time management which includes developing effective study habits, critically analyzing problems and assignments, knowing one's peak hour of concentration, learning effective memorization techniques, thinking aloud and most importantly, avoid procrastination (Sansgiry, et al., 2004).

\subsection{External Motivation}

Psychologists and researchers believed that motivation is the unique ingredient for learning (Biehler \& Snowman, 1986); and among of all personal and psychological variables that have attracted researchers in the area of academic performance, motivation seems to be gaining more popularity and leading factor as compared to other variables (Tella, 2007). External motivation is said to be evident when a person carries out an action because there will be a tangible valuable payoff such as good grades, an increment of salary, or recognition. The action is performed to gain an external consequence or reward. These rewards are unrelated to the action and are, therefore, referred to as external motivation (Covington, 2000). The perceived availability of social support which is a type of external motivations may influence a student academic performance (e.g., Cutron, Cole, Colangelo, Assouline, \& Russell, 1994).

\subsubsection{The Relationships between Time Management, External Motivation and Students' Academic Performance}

Time management can be defined as the ability of a person to accomplish the desired goals either in the short-term or long-term with the effective allocation of time. In this study, time management means students are able to balance their academic activities and extracurricular activities which reflected on the students' Grade Point Average (GPA) for each semester. External motivation in this particular study related to the supportive actions that are given by students' lecturers, friends, together with family members as we denote it as social support. With the strengthening forces of these bonds, students might be motivated and able to perform well in their academic arena.

\subsubsection{Theoretical Background: Motivation Theory}

They are several theories on motivation such as Frederick Herzberg and Abraham Maslow theories of motivation (Herzberg, Mausner \& Snyderman, 1959; Maslow, 1970). These theories are among the earliest behavioural theories embraced by the American businesses and widely adopted by many studies in this area of study. Maslow theory believed that employee's needs are ranked (Herzberg, Mausner \& Snyderman, 1959). This is popularly known today as Maslow Hierarchy of Needs. The theory believed in the satisfaction of various human needs and how people pursue these needs according to their levels.

Herzberg, a psychologist, proposed a theory about job factors that motivate employees. According to Herzberg's (1959) motivation theory, certain factors determine people satisfaction or performance at their workplace (Maslow, 1970). The theory assumed that motivators (satisfiers) are linked with long-time positive effects in performance. Herzberg found that certain factors such as personal achievement and salary influence peoples' performance. In the context of this study, two key factors are identified to motivate student's academic performance in UUM. They include time management and external motivation. The time management can be seen as the internal motivation as it has to deal with the individual student while the external motivation is concerned with other motivators outside the student's domain. In other words, they are those motivators from the university environment for the students to achieve a better academic performance. Therefore, it is assumed in this study that motivation in terms of proper time management and external motivation from the University will propel and motivate students to achieve a high level of academic performance. Thus, Herzberg theory of motivation becomes very relevant to underpin this study with the assumption that motivational factors (e.g. time management and external motivation) will encourage students to achieve better academic performance.

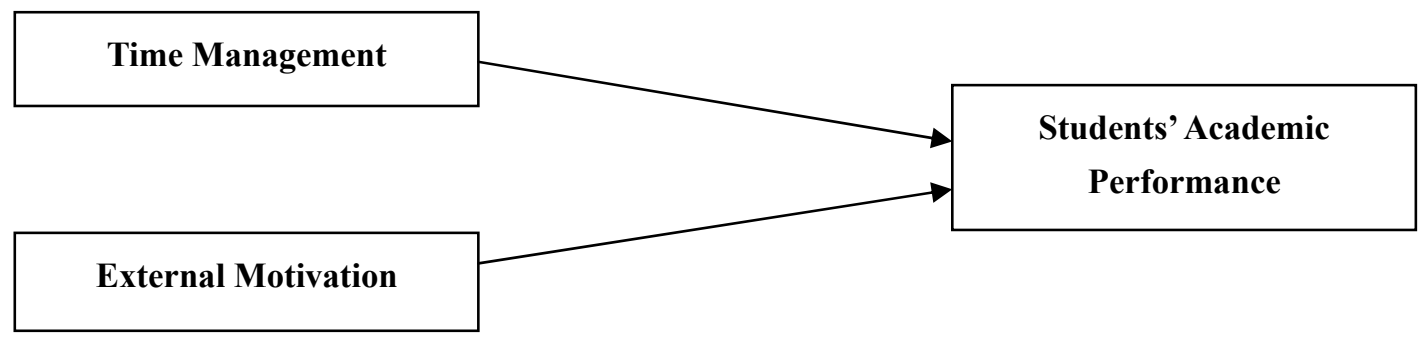


Based on the above literature reviewed and coupled with the constructed research framework, the study draw out the following hypotheses:

H1: There is a significant relationship between time management and students' academic performance of UUM students.

H2: There is a significant relationship between external motivation and students' academic performance of UUM students.

\section{Methodology}

\subsection{Research Design}

The study applied a cross-sectional research design technique. Sekaran and Bourgie (2009) affirmed that cross-sectional design is suitable in a social science studies such as the present study. It is faster and easier in terms of gathering information within a limited time. Our research approach is purely quantitative with a questionnaire survey method. Lucky and Minai (2011) and Minai and Lucky (2011) support quantitative research approach with a questionnaire survey method when there is a time limit to gather or collect data for the study.

\subsection{Population and Sampling Technique}

Our study population covers all UUM students with emphasis in final year BBA students. This choice of BBA students is in line with their larger population among other departments in the university. Researchers used the convenient sampling technique to select $150 \mathrm{BBA}$ students who are in their final year. The essence of choosing the final year students is that they have experience in managing time.

\subsection{Measurement of Variables}

To measure the extent which the responses from the respondents measure the variables under investigation, time management was measured using 7 items reflecting students' personal academic planning, control and how they handle assigments adopted Lucky (2011). External factor variable was equally measured using 4 items reflecting students' rewards and compitition adapted from the previous work... Similarly, students academic performance construct was also measured with 4 items reflecting academic grade, achievement and accomplishment adapted from Lucky (2011). Accordingly, all items in the scale were measured on 5-point Likert-scales ( $1=$ strongly disagree, $5=$ strongly agree) .

\subsection{Data Collection Procedure}

A survey questionniare through self-administered also called drop-off and pick procedure was employed to distribute the questionniare and gatherered information from the respondents who are students from UUM. Out of the 150 survey questionnaires distributed to the respondents, only 113 completed questionnaires were returned filled which ultimately provided a $75 \%$ response rate.

\subsection{Descriptive Statistics}

Table 1 below shows the descriptive analysis result of the respondents. To summarise the profile of the respondents, a descriptive analysis was conducted and the result in Table 1 indicates that $31.0 \%$ of the respondents are male, while the remaining 78 respondents represent the female group forming $69.0 \%$ of the total response. For the distribution of the age of the respondents is classified into 5 categories: (i) 19 and below, (ii) 20-21, (iii) 22-23, (iv) 24-25 and (v) 26 and above. The majority of the respondents are between the ages of $22-23$ years. This group is represented by 91 respondents forming $80.5 \%$ of the total response while 13 respondents represent age group of $20-21$ years which form a percentage of $11.5 \%$ of the total response. 6 respondents are from the age group 24-25 years with the percentage of $5.3 \%$ of the total response. 2 respondents are from the age group 19 years and below which the percentage of $1.8 \%$ of the total response. Equally, 1 respondent are from the age group between 26 years and above with the percentage of $0.9 \%$. For CGPA, it is grouped into five, below 2.00, 2.00-2.49, 2.50-2.99, 3.00-3.49, and 3.40-4.00. Out of the 113 respondents of the sample in this study, $65(57.5 \%)$ respondents indicate CGPA between 3.00-3.49, 27 (23.9\%) respondents indicate CGPA between3.40-4.00, 19 (16.8\%) respondents indicate CPGA between 2.50-2.99, while $1(0.9 \%)$ respondent indicate CGPA between $2.00-2.49$ and below 2.00 respectively. 
Table 1. Descriptive analysis $(\mathrm{n}=113)$

\begin{tabular}{ccc}
\hline & $\mathrm{N}=$ sample & Percentage (\%) \\
\hline Gender: & 35 & 31.0 \\
Male & 42 & 69.0 \\
Female & & \\
Age: & 2 & 1.8 \\
19 and below & 13 & 11.5 \\
$20-21$ & 91 & 80.5 \\
$22-23$ & 6 & 5.3 \\
$24-25$ & 1 & 0.9 \\
26 and above & & \\
CGPA: & 1 & 0.9 \\
Below 2.00 & 1 & 0.9 \\
$2.00-2.49$ & 19 & 16.8 \\
$2.50-2.99$ & 65 & 57.5 \\
$3.00-3.49$ & &
\end{tabular}

\subsection{Reliability and Correlation Analysis Result}

Julia (2007) asserts that the reliability of scale differs greatly and it depends on the sample of research or study. Its importance in research work has made very necessary for researchers to check that each of the scale is very reliable for the sample of the research work. In line with this, there is a need to check the internal consistency of the scales used in the study. The Cronbach's Alpha indicator which is the common predictor of the internal consistency is adopted in this study. Julia (2007) suggests a Cronbach' Alpha coefficient of more than 0.5 to be accepted level especially if the scale of the study has less than 10 units. Alam (2009) uses a Cronbach's Alpha of coefficient of more than 0.60 in his study whereas Micheal, Jackson \& Wroblewski (2000) use a Cronbach's Alpha coefficient above 0.5. Table 4.4 below demonstrates the result of Cronbach's Alpha coefficient used in checking the reliability of the instruments in the study. The below indicates a KMO and Bartlett's test result of above 0.5 which indicates that the sample of the study is normal and suitable for further analysis (Chakraborty, 2010; Trent et al. 2009). The correlation analysis which was used to confirm the hypotheses before further analysis indicates that both hypotheses ( $\mathrm{H} 1$ and $\mathrm{H} 2$ ) were confirmed by the correlation analysis result in Table 2 below.

Table 2. Cronbach's Alpha and correlations of the variables $(\mathrm{N}=113)$

\begin{tabular}{lcccc}
\hline Variables & $\alpha$ & 1 & 2 & 3 \\
\hline 1. Time Management & .786 & 1 & & \\
2. External Motivation & .715 & $.611^{* *}$ & 1 & \\
3. Students' Academic Performance & .747 & $.547^{* *}$ & $.368^{* *}$ & 1 \\
\hline
\end{tabular}

Note, $n=113,{ }^{*} p<.05, * * p<.01$

$\mathbf{H}_{1}$ : There is significant relationship between time management and students' academic performance. (H1 has been confirmed; $\mathrm{p}>0.01$ )

$\mathbf{H}_{2}$ : There is significant relationship between external motivation and students' academic performance. (H2 has been confirmed; $\mathrm{p}>0.01$ )

\section{Analysis Result}

The Multiple Regression Analysis result 


\begin{tabular}{|c|c|c|c|c|c|c|}
\hline Variable & $\mathrm{R}$ & R Square & $\mathrm{F}$ & Bata & $\mathrm{t}$ & Sig. \\
\hline Time management & \multirow[b]{2}{*}{.549} & \multirow[b]{2}{*}{.301} & \multirow[b]{2}{*}{23.734} & .515 & 5.110 & .000 \\
\hline External motivation & & & & .054 & .533 & .595 \\
\hline
\end{tabular}

According to Maholtra (2002), regression analysis can be used for analyzing on relationship between the dependent variable and independent variables. Multiple regression equation: $Y=a+\beta X 1+\beta X 2+e$, where:-

$\mathrm{Y}=$ Dependent variable (Students' Academic Performance)

$\mathrm{a}=$ Constant value under standardized coefficient column

$\beta=$ Beta value for independent variables

$\mathrm{X} 1=$ Independent variable 1 (Time Management)

$\mathrm{X} 2$ = Independent variable 2 (External Motivation)

So that: $\mathrm{Y}=\mathrm{a}+0.515 \mathrm{X} 1+0.054 \mathrm{X} 2+\mathrm{e}$

From the regression equation indicates that time management and external motivation are positively related with students' academic performance in UUM. The coefficients $(\beta \mathrm{s})$ show the effects on the dependent variable of unit increases in any of the independent variables. This equation also indicates that beta value of time management is the highest, followed by external motivation. From the above regression equation, it can be concluded that if there is an increase in time management and external motivation then the students' academic performance will increase by 0.515 and 0.054 respectively.

The Beta value for time management is 0.515 at p-value equals to 0.000 and the Beta value for external motivation is 0.054 at p-value equals to 0.595 . Therefore, external motivation is found to has insignificant and no relationship with the students' academic performance in UUM. Time management is found to have significant and positive relationship with students' academic performance in UUM at significant level of 0.000 .

The following part will present the findings of the research. The table below shows relationship between dependent variable and independent variables. One way-ANOVA and t-test were used to determine if there statistically differences in the students' academic performance in UUM when grouped by time management and external motivation.

The result from regression analysis based on two independent variables which are time management and external motivation can be seen in Table 3. Based on the model, the $\mathrm{R}(0.549)$, which is the correlation with the dependent variable. After taking all the inter correlation among two independent variable, the $\mathrm{R}^{2}(0.301)$, and $\mathrm{R}^{2}$ adjusted (0.289). We can clarify that 30.1 percent of the two independent variables influence dependent variable which is students' academic performance. $\mathrm{R}^{2}(0.301)$ or 30.1 percent indicates that students' academic performance in UUM is explained by the independent variables and the rest of 69.9 percent is still left unexplained. There are other factors or variables that could affect students' academic performance. The F value of 23.374 is significant at the 0.000 level. Therefore, the result can be concluded that with 30.1 percent of the variance (R-Square) in students' academic performance were significant.

\section{Discussion on Findings}

The primary objective of the study was to identify the influence of time management and external motivation on students' academic performance. The study revealed the interesting result that is highly important for students' academic success. Among the study variables, the issue of time management has been found highly significant and positively related to students' academic performance, and the study result supports the claim of Talib and Sansgiry (2012) study conducted in Asian context. Earlier, the similar result was also reported by the study of Sansgiry et al. (2004) where researchers argued that time management is a critical factor for higher academic performance, and students should be provided with various skills and techniques of time management. Realistically, one can assume that better time management may generate superior quality of work. If students can improve the skills in time management, they may not have to depend on last-minute studying before examination, thus improving academic performance. The results of the study revealed through the applicability of Pearson's correlation and multiple regression analyses. The following discussions have been made based on the result of hypotheses testing.

The first research objective was to investigate the relationship between time management and students' academic performance. The study result indicated that time management (beta value $=0.51 .5$, $\mathrm{p}$-value $=0.000$ ) has significant contribution to the area of students' academic performance. This means that time management is significant at $\mathrm{p}<0.001$ with $51.5 \%$ contribution to students' academic performance for every one unit increase in 
time management variable. The present study result supported and demonstrated the consistency with the past studies such as Sansgiry et al. (2004); Necati \& Sevil, (2010); Kaushar (2011); Griffin et al. (2012) who asserted time management contributes significantly and positively to the students' academic performance. Thus, the result tested and verified the model of students' academic performance particularly in the context of Malaysia. Kaushar (2011) stated in the study that the appropriate time management skill plays a vital role in improving students' academic performance which includes setting goals and priorities, time management mechanism (to do list), and proper organization of using time. The researcher also argued that students who lag behind in terms of academic performance actually fail to allocate sufficient time to high priority tasks due to lack of time management skills.

The second research objective is about testing the significant contribution of external motivation and students' academic performance. The previous study, for example, Emmett and McGee (2013) had proven a significant relationship between external motivation and students' academic performance in USA context. However, the present study has found an opposite result which shows no significant relationship between external motivation and students' academic performance in the context of Malaysia. The plausible reason for such result could be the contextual effects

\section{Limitations and Conclusions of the Study}

There are some limitations to this study that should be considered before generalizing the results. The sample size of the study was small, and thus the results may not be generalized to all students in Malaysia. This study only included the final year students of BBA program of one public university in Malaysia which reduces the generalizability of the results. This study can be considered as a good starting point for more studies on the same aspect of business education. Thus, future study should include students from various programs of business education of other public and private universities in the country. The other limitation of the study was the sampling technique applied into this research. The data was collected using convenient sampling technique which also reduces the generalizability of the study due to the higher tendency to influence the result. It is also noticeable that the indicator used for academic performance was students' self-reported CGPA scores. Thus, there is a possibility to provide inaccurate grade point average, and this might constitute a bias in this study. There is another issue that might also be considered as the limitation of the study that some students may not clearly understand the items used in our questionnaire accurately to reflect their opinions and behaviors.

In conclusion, this study has developed a clear dimension on the determinants of students' academic performance. The first objective of the study was to identify the influence of time management on students' academic performance. The hypotheses tested and the results indicated significant and positive relationship between time management and their academic performance. The findings reported in this study justify the importance of time management to academic performance. Thus, adequate emphasis should be given to improve students' ability to manage their time effectively and efficiently in order to gain academic excellence. The finding of the study has practical implication especially for students, parents, and the university authority by demonstrating the various techniques of time management skills, and should engage students in different programs that help them to manage their time efficiently. This study has also confirmed that the external motivation has no real effect on students' academic performance. This finding is also interesting as it claims different results. Therefore, it is important to know for all stakeholders that apart from other important factors, time management will also significantly influence students' academic performance and this dimension should be taken care of when examining the predictors of students' academic performance.

\section{References}

Afzal, H., Ali, I., Khan, M. A., \& Hamid, K. (2010). A study of university students' motivation and its relationship with their academic performance. International Journal of Business and Management, 5(4), 80-88. http://dx.doi.org/10.5539/ijbm.v5n4p80

Barry, J. (2006). The effect of socio-economic status on academic achievement. Master Thesis. Wichita State University.

Bellott, F. K., \& Tutor, F. D. (1990). A Challenge to the Conventional Wisdom of Herzberg and Maslow Theories. Paper presented at the Nineteenth Annual Meeting of the Mid-South Educational Research Association. New Orleans, LA.

Biehler, R., \& Snowman, J. (1986). Psychology Applied to Teaching (5th ed.) Boston: Houghton Mifflin Company.

Britton, B. K., \& Abraham, T. (1991). Effects of time-management practices on college grades. Journal of Educational Psychology, 83(3), 405-410. http://dx.doi.org/10.1037/0022-0663.83.3.405 
Caro, D. H. (2009). Socio-economic status and academic achievement trajectories from childhood to adolescence. Canadian Journal of Education, 32(3), 558-590.

Cohan, B. I., \& Khan, R. M. (2010). Impact of parental support on the academic performance and self-concept of the student. Journal of Research and Reflections in Education, 4(1), 14-26.

Cosden, M., Morrison, G., Gutierrez, L., \& Brown, M. (2004). The effects of homework programs and after-school activities on school success. Theory into Practice, 43(3), 220-226. http://dx.doi.org/10.1207/ s15430421tip4303 8

Devadoss, S., \& Foltz, J. (1996). Evaluation of factors influencing student class attendance and performance. American Journal of Agricultural Economics, 78, 499-508. http://dx.doi.org/10.2307/1243268

Emmett, J., \& McGee, D. (2013). Extrinsic Motivation for Large-Scale Assessments: A Case Study of a Student Achievement Program at One Urban High School. The High School Journal, 96(2), 116-137. http://dx.doi.org/10.2307/1243268

Fisher, S., \& Hood, B. (1987). The stress of the transition to university: A longitudinal study of psychological disturbance, absent-mindedness and vulnerability to homesickness. British Journal of Psychology, 78, 425-441. http://dx.doi.org/10.1111/j.2044-8295.1987.tb02260.x

Gall, M. D. (1988). Making the grade. Rocklin.CA: Prima.

Gloe, D. (1999). Study habits and test taking tips. Dermatology Nursing, 11(6), 439-449.

Günçer, B., \& Köse, M. R. (1993). Effects of family and school on Turkish students' academic performance. Education and Society, 11(1), 51-63.

Herzberg, F. (1959). The Motivation to Work, John Wiley and Sons. New York, NY.

Herzberg, F., Mausner, B., \& Snyderman, B. B. (1959). The Motivation to Work (2nd ed.). New York: John Wiley \& Sons.

James, D., \& Chilvers, C. (2001). Academic and non-academic predictors of success on the Nottingham undergraduate medical course 1970-1995. Medical Education, 35, 1056-1064. http://dx.doi.org/10.1046/ j.1365-2923.2001.01042.x

Jeynes, W. H. (2002). Examining the effects of parental absence on the academic achievement of adolescents: The challenge of controlling for family income. Journal of Family and Economic Issues, 23(2), 189-210. http://dx.doi.org/10.1023/A:1015790701554

Juvonen, J., \& Wentzel, K. R. (1996). Social motivation: Understanding children's school adjustment. New York: Cambridge University Press. http://dx.doi.org/10.1017/CBO9780511571190

Kaushar, M. (2013). Study of impact of time management on academic performance of college students. Journal of Business and Management, 9(6), 59-60.

Lakey, B., \& Cohen, S. (2000). Social support theory and measurement. In S. Cohen, L. G. Underwood, \& B. H. Gottlieb (Eds.), Social support measurement and Intervention (pp. 29-52). New York: Oxford University Press.

Longman, D. G., \& Atkinson, R. H. (1988). College learning and study skills. St. Paul, MN: West.

Lucky, E. O. -I., \& Minai, M. S. (2011). Re-Investigating the Effect of Individual Determinant, External Factor and Firm Characteristics on Small Firm Performance during an economic downturn. African Journal of Business Management, 5(26), 10846-10854.

Macan, T. H., Shahani, C., Dipboye, R., \& Phillips, A. P. (1990). College students' time management: Correlations with Academic performance and stress. Journal of Eductional Psychology, 82(4), 760-780. $\mathrm{http}: / / \mathrm{dx}$.doi.org/10.1037/0022-0663.82.4.760

Maslow, A. H. (1970). Motivation and Personality (2nd ed.). New York: Harper and Row.

Minai, M. S., \& Lucky, I. O. E. (2011).The Moderating Effect of Location on Small Firm Performance: Empirical Evidence. International Journal of Business and Management, 6(10), 178-192.

Necati, C., \& Sevil, F. (2010). The Relationship between time management skills and academic achievement of potential teachers. Educational Research Quarterly, 33(4). 
Robbins, S., Lauver, K., Le, H., Davis, D., Langley, R., \&Carlstrom, A. (2004). Do psychosocial and study skill factors predict college outcomes? A meta-analysis. Psychological Bulletin, 130, 261-288. http://dx.doi.org/10.1037/0033-2909.130.2.261

Sansgiry, S. S., Kaawatkar, A. A., Dutta, A. P., \& Bhosle, M. J. (2004). Predictors of Academic Performance at two universities: The effects of academic progression. American Journal of Pharmaceutical Education, 68(4), 1-7. http://dx.doi.org/10.5688/aj6804103

Sansgiry, S., Bhosle, M., \& Sail, K. (2006). Factors that affects academic performance among pharmacy students. American Journal of Pharmaceutical Education, 70(5), 104-120. http://dx.doi.org/10.5688/aj7005104

Svanum, S., \& Zody, Z. B. (2001). Psychopathology and college grades. Journal of Counseling Psychology, 48(1), 72-76. http://dx.doi.org/10.1037/0022-0167.48.1.72

Talib, N., \& Sansgiry, S. (2012). Determinants of Academic Performance of University Students. Pakistan Journal of Psychological Research, 27(2), 265-278.

Tella, A. (2007). The impact of motivation on students' academic achievement and learning outcomes in Mathematics among secondary school students in Nigeria. Eurasia Journal of Mathematics, Science \& Technology Education, 3(2), 149-156.

Trueman, M., \& Hartley, J. (1996). A comparison between the time-management skills and academic performance of mature and traditional-entryuniversity students. Higher Education 32, 199-215. http://dx.doi.org/10.1007/BF00138396

Tutor, F. D. (1986). The Relationship between Perceived Need Deficiencies and Factors Influencing Teacher Participation in the Tennessee Career Ladder. Doctoral dissertation. Memphis State University, Memphis, TN.

Van Etten, S., Pressley, M., McInerney, D., \& Darmanegara, A. (2008). College seniors' - Theory of their academic motivation. Journal of Educational Psychology, 100.

Vansteenkiste, M., Zhou, M., Lens, W., \& Soenens, B. (2005). Experiences of autonomy and control among Chinese learners: Vitalizing or immobilizing? Journal of Educational Psychology, 97(3), 468-483. http://dx.doi.org/10.1037/0022-0663.97.3.468

Walter, T., \& Siebert, A. (1981). Student success. New York: Holt, Rinehart and Winston.

Womble, P. (2003). Impacts of Stress factors on college student's academic performance. Undergraduate journal of Psychology, 16(1), 16-23.

\section{Copyrights}

Copyright for this article is retained by the author(s), with first publication rights granted to the journal.

This is an open-access article distributed under the terms and conditions of the Creative Commons Attribution license (http://creativecommons.org/licenses/by/3.0/). 